\title{
The impact of perceived enjoyment on team effectiveness and individual learning in a blended learning business course: The mediating effect of knowledge sharing
}

\author{
Chun-Yu Lin \\ National Taipei University, Taiwan \\ Chung-Kai Huang \\ National Taipei University of Business, Taiwan \\ Chao-Jung Ko \\ National University of Tainan, Taiwan
}

\begin{abstract}
With advances in information and communication technology, blended learning has become an effective approach for highlighting disciplinary effects and accommodating student population diversity. Faculty members in business schools have developed an understanding of design approaches that have evolved and selected appropriate designs for blended courses. This study combines the approaches of blended and team-based learning to support a management course. This study involved 197 undergraduate business students from two Taiwanese universities. Their perceptions of the course were elicited through survey questions. Subsequent quantitative analysis has revealed the relationships among learners' perceived enjoyment, knowledge sharing, team effectiveness, and perceived individual learning. This study documents education benefits, pedagogical implications, and research limitations in applying this approach to business education. Those points are developed along with recommendations regarding future research directions.
\end{abstract}

Implications for practice or policy:

- In blended team-based learning settings, educators need to consider the importance of creating an enjoyable learning environment in facilitating students' knowledge sharing processes and team-based work.

- Educators should keep investigating blended team-based and focus on building an effective mechanism for students to share knowledge in different learning phases in order to improve the quality of their team effectiveness and perceived individual learning.

- Higher education institutes should promote the benefits of applying blended teambased in business curricula as well as provide adequate facilities and training for business educators and students in order to ensure teaching and learning quality.

Keywords: blended learning, knowledge sharing, team effectiveness, perceived individual learning

\section{Introduction}

Business education and technology have both evolved in order to embrace the complexities of today's everchanging business environment (Caza, Brower, \& Wayne, 2015). The design of curriculum and learning spaces in business education is becoming essential, because it not only provides university students with the knowledge for business professions but also helps them acquire the necessary abilities, skills, and characteristics needed to thrive in future workplaces (Whitaker, New, \& Ireland, 2016). A practical set of workplace competencies that include the skills of communication, team building, decision-making, and thinking that is innovative and sustainable should never be overlooked (Audebrand, Camus, \& Michaud, 2017). In particular, teamwork and collaboration are two important skills that help business students negotiate differing perspectives and reach a consensus for accepted decisions in order to achieve team objectives and goals (Ritter, Small, Mortimer, \& Doll, 2018).

To facilitate students' meaningful inquiries concerning subject content and the collaborative learning process, information and communication technology (ICT) has been incorporated and its potential to 
enhance the quality of higher education has been tapped into (Arbaugh, 2014; M. L. Hung \& Chou, 2015). Nevertheless, possible drawbacks remain that derive from the use of technology-mediated learning tools in an educational context (Urh, Vukovic, Jereb, \& Pintar, 2015). Decreases in social connectedness may take place when fully online learning is implemented (Slagter van Tryon \& Bishop, 2009), but social connectedness in class should be an even more important part of the success of online learning (Rovai, 2002). The consideration of social connectedness is particularly important to today's university students, as this population was raised in a digital- and media-saturated world and is prone to be more tech-savvy, communicative-based, and team-oriented compared with the older generations (Severt, Fjelstul, \& Breiter, 2013). Research on the relationship between the features of blended learning (BL) and the operation of learning communities has grown in higher education (Szeto, 2015). Nevertheless, relevant empirical studies remain scarce in business education, and thus this study intends to expand the research context to the business schools.

Some researchers (e.g., Oh \& Syn, 2015) have stated that university students are used to using social media networking, ICT systems, and new media to form social relationships, share information and knowledge, and construct identities both in their inquiry of individual learning and their development of collaborative group projects. Consequently, the adoption of BL involving face-to-face and online modes has been promoted to spur an effective and efficient educational experience in higher education (Alammary, Sheard, \& Carbone, 2014). Due to concerns about learners' learning preferences and spaces, social connection on technology-mediated learning processes, and learning outcomes, this study adopted the notions of social exchange (Blau, 1964) and social learning (Bandura, 1977) theories to form a research framework and pose questions. The use of these two theories was suggested by two of the researchers (C. K. Huang \& Lin, 2017) based on their findings that the new behaviours taking place in blended classrooms can be acquired by observing and imitating others, as well as by the nature of exchanges among different teams.

There are three main reasons why this study is significant and compelling. First, scholars from higher education have experimented with and explored BL course design and keep suggesting that more attention on the empirical findings can be paid in different areas of practice (Owston, York, \& Murtha, 2013). In blended business education, the volume and quality of research have increased dramatically in the area of information science, management, and multidisciplinary studies (Arbaugh et al., 2009). However, few studies have been conducted in the field of human resource management during the past decade, which underpinned the launch of this project. Second, current university students are more willing to accept BL (Wanner \& Palmer, 2015) because they enjoy increased flexibility in their personalised learning and accessibility through interactive, collaborative, and well-structured learning activities via either online or face-to-face encounters (Mirriahi, Alonzo, McIntyre, Kligyte, \& Fox, 2015). ICT possesses the capacities and serves as an enabler for university students' professional learning and development (Brown, 2016). Third, the literature encourages endowing a sense of responsibility for assigned learning tasks and implementing BL courses that are influenced by learners' attitudes about, and perceptions of, learning and interactivity both in and outside the classroom (Owston et al., 2013; Pinto-Llorente, Sánchez-Gómez, García-Peñalvo, \& Casillas-Martín, 2017). Smyth, Houghton, Cooney, and Casey (2012) further noted that the benefits of BL may include accessibility, flexibility, autonomy, responsibility, and application to practice, all of which tend to enhance learning.

Thus, by reforming a business course as a BL course, this study looked into learners' enjoyment of BL, their interactive behaviours, and their perceptions of teamwork and learning outcomes in co-created learning spaces. Accordingly, the aim of this study was to examine the impact that learners' individual pleasant learning experiences had on team effectiveness and learning in a BL context. Moreover, this study represents an attempt to explore the importance of learners' knowledge and sharing behaviour on teamwork and learning outcomes from social perspectives.

BL

BL has generally been defined as a combination of the attributes from both traditional face-to-face and online learning environments (Arney, 2015). Some researchers (Porter, Graham, Spring, \& Welch, 2014) have described $\mathrm{BL}$ as a hybrid of traditional instructor-led teaching with online learning or electronic supplements; and thereby instruction is presented both in the classroom and online. In terms of delivery methods, BL programs may include a multitude of learning tools, such as real-time or virtual collaboration software, self-paced web-based courses, and electronic performance support systems embedded within a 
job-task environment (Singh, 2003). Given that BL incorporates the advantages of online learning and the benefits of traditional class learning, the flexibility and richness of BL design can spur an effective and efficient educational experience regarding time, place, and convenience for instructors and learners (Vaughan, 2007).

According to Garrison and Kanuka (2004), the effectiveness of BL depends on its ability to facilitate community building and its inquiry of learning. The relationship between the adoption of BL and the formation of a learning community has been identified by previous researchers (Garrison \& Vaughan, 2013). This type of community-based inquiry provides spaces for open and free discussion, negotiation, critical debate, and agreement, which are the typical characteristics featured in business education (Daspit \& D'Souza, 2012). A community is influential in engendering commitment and in ensuring that learners move through different inquiry phases in a progressive manner (Garrison \& Vaughan, 2008). That is, community-based inquiry enables the possibility of integrating physical and online learning spaces to meaningfully and dynamically foster knowledge construction and experience sharing among student cohorts (Lai, 2011). Learners may therefore perceive enjoyment and be more willing to share knowledge.

\section{Perceived enjoyment and knowledge sharing}

Perceived enjoyment can be viewed from two perspectives (Moghavvemi, Sharabati, Paramanathan, \& Rahin, 2017). One of them is the enjoyment of helping others. Hsu and Lin (2008) suggested that enjoyment is a key factor in the intention to participate in social networks. When people are provided with appropriate opportunities to interact with and assist others, the possibilities for perceived enjoyment increase. One of those opportunities can be offered through knowledge sharing.

According to S. Wang and Noe (2010), knowledge sharing refers to "the provision of task information and know-how to help others and to collaborate with others to solve problems, develop new ideas, or implement policies or procedures" (p. 117). Since knowledge sharing involves a reciprocal exchange of knowledge and skills (Moghavvemi et al., 2017), it can be considered a type of social exchange (Bock, Zmud, Kim, \& Lee, 2005) that allows people to interact and furthermore to receive external rewards such as reciprocal benefits and relationships (Hsu \& Lin, 2008).

In addition, during the knowledge-sharing process, people contribute knowledge and therefore perceive pleasure obtained from helping others (Kankanhalli, Tan, \& Wei, 2005), which may enhance their motivation to share knowledge. Hence, we proposed the following hypothesis:

H1. Perceived enjoyment is positively associated with knowledge sharing.

\section{Perceived enjoyment and team effectiveness}

Perceived enjoyment, viewed as an example of intrinsic motivation, can influence individuals' acceptance of a learning experience (J. H. Huang, Lin, \& Chung, 2007). When learners feel that the learning experience is pleasurable to them, they perceive enjoyment (Gomez, Wu, \& Passerini, 2010). This perception can lead to their engagement in activities, and then collaboration among individuals can occur.

Team-based learning in business can present authentic scenarios and discipline-specific tasks rooted in realworld situations that motivate students to solve problems they may encounter in the targeted workplace (Timmerman \& Morris, 2015). The interdependence theory suggests that it is natural for individuals within a team to work collaboratively in order to achieve a common goal, which has a significant impact on team effectiveness (Alsharo, Gregg, \& Ramirez, 2017). In this study, we argue that individuals who perceive higher enjoyment in $\mathrm{BL}$ are more apt to engage in activities, which results in better team collaboration. Thus, we proposed the following hypothesis:

H2. Perceived enjoyment is positively associated with team effectiveness.

\section{Knowledge sharing and team effectiveness}

Knowledge sharing is critical to effectiveness or satisfaction of organisations and individuals (Dutta, 1997). Reciprocal knowledge sharing among team members can enhance their problem-solving abilities and thus 
improve team effectiveness (Nelson \& Cooprider, 1996). Pangil and Chan (2014) found that team effectiveness is related to team members' willingness to share knowledge with each other. Although the success of knowledge sharing depends on individual team members' willingness to share the knowledge they possess, they may be reluctant to share knowledge due to the fear of a loss of individual competitiveness and of the additional effort required for knowledge codification (Lu, Lin, \& Leung, 2012).

Trust within the team can encourage team members' relationship-building skills, which may reduce their fears and stimulate their willingness to exchange knowledge. Trust impacts team effectiveness (Alsharo et al., 2017). The more the team members share knowledge with each other, the more trust they have in each other, and the more effective the team is. Therefore, we proposed the following hypothesis:

H3. Knowledge sharing is positively associated with team effectiveness.

Alsharo et al. (2017) found that knowledge sharing positively influenced both trust and collaboration among team members. Trust is beneficial to effective collaboration. A study by M. H. Wang, Yang, and Wu (2006) showed that team members' interactive processes can influence team effectiveness via the mediation of knowledge sharing. To ensure team members' collaboration to share knowledge, their reciprocal help is required. And when individuals perceive reciprocal help, they tend to also perceive enjoyment. Therefore, the following hypothesis was suggested:

H4. Knowledge sharing will mediate the relationship between perceived enjoyment and team effectiveness.

\section{Perceived enjoyment and individual learning}

Gomez et al., (2010) noted that when learners perceive a learning activity or experience as pleasant and satisfactory, they perceive enjoyment and enter a state of cognitive absorption with the learning materials. Cognitive absorption reveals the state of learners' deep involvement with the learning materials. Higher education learners perceive enjoyment in learning experiences that parallels their involvement with learning materials: hence, they value learning more. The higher learners perceive enjoyment in learning experiences that parallels their involvement with learning materials, the more they value learning.

Although the study by Gomez et al. (2010) indicated a positive correlation between perceived enjoyment and perceived learning, their online discussions were implemented in a WebBoard forum in a Western context. Since different learning environments may influence learners' experiences and learning outcomes differently, it is worth looking into if such a positive correlation could also be found in a different online environment, such as Facebook, which is more familiar to Taiwanese students but ranked by some Western instructors as their least favourite delivery method (Ritke-Jones, 2010), in an Eastern context. Therefore, we proposed the following hypothesis:

H5. Perceived enjoyment is positively associated with perceived individual learning.

\section{Knowledge sharing and individual learning}

Sharing one's knowledge with others is considered as a beneficial learning strategy that allows mutual learning due to feedback (Lu et al., 2012). For knowledge recipients, the effective application of knowledge confirms knowledge validity. In Vygotsky's (1978) social-cultural theory of learning, knowledge acquisition involves two planes: the social/individual and the public/private. On the social plane, learners acquire new concepts and strategies through interactions with those who are more knowledgeable. Then individual learners apply what they learn to other contexts that initiate meanings and interpretations through interactions. After learning emerges on the public plane, individual learners understand, adjust, and implement their acquired knowledge in the private area.

Knowledge sharers may gain a better grasp of knowledge they previously did not understand well or may gain new insights due to questions raised or feedback provided by recipients. They also need to fully understand the topic in order to successfully explain it to recipients. Otherwise, they may have to deepen their own understanding until they find a better way to organise and explain the knowledge before sharing 
it. Therefore, knowledge sharing is a learning process for both sharers and recipients (S. Wang \& Noe, 2010). Based on the above arguments, we proposed the following hypothesis:

H6. Knowledge sharing is positively associated with perceived individual learning.

Knowledge transmission or diffusion among individuals can occur through performing activities such as knowledge sharing (S.-W. Hung \& Cheng, 2013). By participating in the activity, knowledge possessors and receivers communicate with each other; and therefore new knowledge can be integrated into receivers' existing knowledge that results in individual learning.

Learning is a process of social participation and interaction (Ma \& Yuen, 2011), which appears in patterns of (for example) collaboration, dialogue, and transferability of knowledge. For Senge (1997), knowledge sharing in terms of learning goes beyond giving things to others or obtaining things from them. Knowledge sharing aims to improve individuals' action capability, which is needed to prepare them to help others. For Wertsch and Bivens (1992), assistance from knowledgeable individuals is a key factor in learning. In addition, individuals must participate actively in learning activities so that higher mental functioning can happen. Individuals may perceive enjoyment from interactions with others and from assisting others. Hence, the following hypothesis was proposed:

H7. Knowledge sharing mediates the relationship between perceived enjoyment and perceived individual learning.

Based on our research ideas, we proposed a research framework which illustrates the seven hypotheses among variables (see Figure 1).

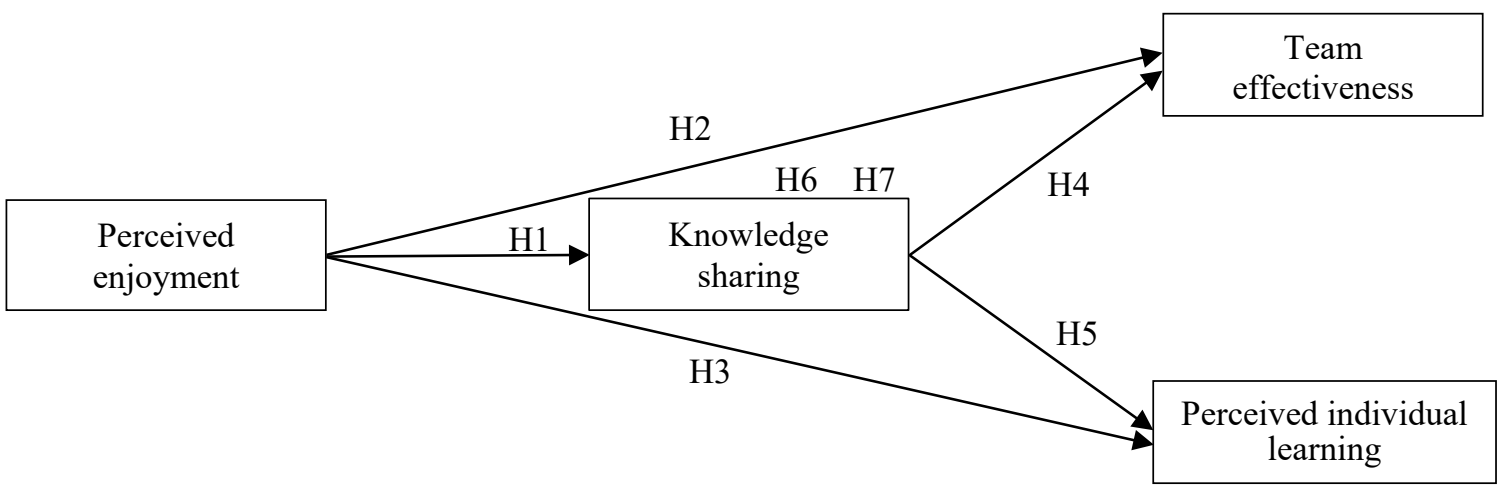

Figure 1. The hypothesised research framework

\section{Research method}

The study received ethical approval from the Research Ethics Office of National Taiwan University. The participants gave informed consent to participate in this study.

\section{Research participants and procedures}

The participants consisted of 197 undergraduate students majoring in business at two universities in Taiwan. All participants took a human resource management course based on blended team-based learning (BTBL) models developed by our research team. A total of 240 surveys were collected, and 197 of them were valid for further data analysis for a response rate of $82.1 \%$. The goal of the course was to help students better understand business theories, functions, and roles as these apply to workplace settings. The teambased course design enables students to collaborate and develop core competencies that can be used to face emerging challenges and issues in future workplaces (McLoughlin \& Luca, 2002). Accordingly, we applied the BTBL model to the course and explored the pedagogical potential of the model in contributing to the growing body of literature on relevant research topics. Based on a constructivist paradigm, the aim of the 
learning-spaces design of this course was to encourage learners to take an active role in developing their own knowledge- and information-seeking processes (Jonassen \& Land, 2012).

This BTBL business course had three learning phases: pre-class, in-class, and post-class modules (C. K. Huang \& Lin, 2017). The students were grouped in cohorts of 5-7 in fixed teams to collaboratively perform the assigned tasks. The team-based design functions as a dynamic incubator to help students develop their competencies and capabilities for the future business environment. The pre-class module required students to preview the online selected videos, approximately 10-30 minutes, based on the content of the textbook chapters, read the provided business cases, and write one reflection journal on the videos and cases. By undertaking the pre-class activities and assignments, the students previewed the class-related materials and shared basic knowledge, ideas, and notes within the team. The pre-class preparation emphasised students' responsibility before coming to class and get themselves prepared for the in-class activities. Next, within the in-class module, the students were asked to apply the concepts, knowledge, and information gained from the pre-class module to some teacher-guided activities. These in-class activities consisted of scenarios that included role play, group discussions, mini presentations, and case studies. By applying the theories to practice, the students were provided with the opportunities to enhance their learning, complete a task, or solve a management problem during the class, where they collaborated with team members and consulted or exchanged ideas with their instructors.

Finally, the students continued the learning experience from the in-class to post-class modules outside of class. In the post-class activities, the students were exposed to different Facebook-supported online discussions or projects in a team-based format to integrate the textbook chapter materials as end-of-the-unit assessments in the post-class module. The continued learning enabled the students to practise their familiarity with the course materials in a holistic way over an extended period of time. Overall, this BTBL business class managed to engage in varied pre-class, in-class, and online activities. When working in teams, they were encouraged to act on initiatives and challenges in various ways to complete their assigned tasks, to facilitate discussions with their teammates and instructors, and to think critically in order to achieve a higher level of learning.

\section{Data analysis}

Drawing on the hypothesised research model and the noted research gap, this study applied a quantitative approach by using a survey to elicit participants' perceptions of their experience in a BL course, as suggested by previous studies (Owston, York, \& Malhotra, 2019; Owston et al., 2013). The survey consisted of four dimensions (perceived enjoyment, knowledge sharing, team effectiveness, and perceived individual learning), which consisted of 26 items in total (see Appendix). The collected data were analysed by using IBM SPSS Statistics 23 and AMOS 22 software. Initial testing began by investigating the correlations between all variables involved in this study. Structural equation modelling (SEM) was further applied to examine the research questions, validate overall model fit, and determine the relationships between the variables.

\section{Measures}

Perceived enjoyment

This construct was assessed by five items adopted from prior studies that assessed perceived enjoyment in an asynchronous computer-supported learning context (Gomez, et al., 2010). It was rated on a five-point Likert scale. A sample statement is "I enjoyed sharing my knowledge of course-related materials with my team through BTBL." The Cronbach's $\alpha$ of this construct was 0.84 .

\section{Knowledge sharing}

Knowledge sharing refers to the interaction and knowledge-sharing behaviours displayed by team members. The construct was assessed by the eight items originally derived from Nelson and Cooprider's (1996) and Senge's (1997) studies. This construct was rated on a five-point Likert scale as well. The Cronbach's $\alpha$ was 0.86 .

Team effectiveness

Seven items were used to assess team effectiveness. The scale was adopted from two previous studies (Lurey \& Raisinghani, 2001; Wang, Yang, \& Wu, 2006). The study of M. H. Wang et al. (2006) also 
used a five-point Likert scale to rate team effectiveness based on two sub-dimensions: performance and quality of work life. One of the study items included limited budgets in teamwork, which was eliminated because it seemed ill suited to the context of this research. Before moving on to confirmatory factor analysis (CFA), exploratory factor analysis (EFA) was conducted to test the adopted scale for performance and quality of work life. The result of the total explained variances was $68.31 \%$. After conducting CFA, one item was eliminated due to a lower loading factor, which left five items that could be used to assess team effectiveness. The Cronbach's $\alpha$ was 0.87 .

\section{Perceived individual learning}

This construct was assessed using the six items adopted from prior studies assessing individual learning in an asynchronous computer-supported learning network context (Gomez et al., 2010). This construct was rated on a seven-point Likert scale. A sample item is "The learning quality of course materials was improved by the team activities." The Cronbach's $\alpha$ was 0.91 .

Some scholars (Hooper, Coughlan, \& Mullen, 2008) suggested .50 as the cut-off for acceptable standardised factor loadings, because these represent the characteristics of the dimensions of each construct, which gauges the reliability of the questionnaire scale. After conducting CFA, some items in the four constructs (perceived enjoyment, knowledge sharing, team effectiveness, and perceived individual learning) were deleted. Overall, there were 21 items in the final questionnaire. In addition, all items were answered by a single source in this study, which could generate a common method variance (CMV). Harman's one-factor test can be used to determine the effect of CMV (Podsakoff, MacKenzie, Lee, \& Podsakoff, 2003). We conducted a Harman's one-factor test to ensure there were no serious problems with CMV in post-hoc testing. The results showed that the first principal component in the total explained variance was $18.70(<50 \%)$, which suggested that there were no serious CMV problems.

\section{Results}

\section{Inter-correlations of variables}

Table 1 shows the means, standard deviations, and the square root of the average variance extracted (AVE) along with the correlations for all variables in this study. All of the variable coefficients fell within the medium range with respect to correlation. Perceived enjoyment was positively related to knowledge sharing $(\mathrm{r}=.50, p<.001)$, team effectiveness $(\mathrm{r}=.45, p<.001)$, and perceived individual learning $(\mathrm{r}=.68, p<$ $.001)$. Both team effectiveness and perceived individual learning were significantly related to knowledge sharing $(\mathrm{r}=.69, p<.001 ; \mathrm{r}=.59, p<.001$, respectively), and team effectiveness was positively related to perceived individual learning $(\mathrm{r}=.49, p<.001)$. According to Hair, Black, Babin, and Anderson $(2010)$, the estimated inter-correlations among most of the constructs in this study were less than the square roots of AVE for each construct, which provided support for the discriminant validity of the scales.

Table 1

Means, standard deviations, validity, and correlations of variables

\begin{tabular}{llllllll}
\hline Variables & Mean & SD & $\mathbf{1}$ & $\mathbf{2}$ & $\mathbf{3}$ & $\mathbf{4}$ & $\mathbf{5}$ \\
\hline 1. Perceived Enjoyment (X) & 3.65 & .48 & $.18^{*}$ & $(.72)$ & & & \\
2. Knowledge Sharing (Me) & 3.96 & .52 & .00 & $.50^{* * *}$ & $(.72)$ & & \\
3. Team Effectiveness (Y1) & 4.01 & .53 & .12 & $.45^{* * *}$ & $.69^{* * *}$ & $(.76)$ & \\
4. Perceived Individual Learning (Y2) & 5.14 & .85 & .13 & $.68^{* * *}$ & $.59^{* * *}$ & $.49^{* * *}$ & $(.82)$ \\
\hline
\end{tabular}

Note. The parenthesis in the correlation matrix represents the square root of AVE. $* * * p<.001, * * p<.01$, $* p<.05 ; N=197$.

\section{Reliability and validity}

Table 2 shows that both the Cronbach's alpha and composite reliability (CR) of each construct exceeded .70 threshold values, so the internal consistency reliability was acceptable (Bagozzi \& Yi, 1989). In addition, AVE for all constructs ranged from .51 to .68, exceeding the threshold value of .50 (Bagozzi \& Yi, 1989; Fornell \& Larcker, 1981), so the results revealed that the convergent validity for all constructs was achieved. 
Table 2

Coefficients for the proposed measurement model

\begin{tabular}{|c|c|c|c|c|c|c|}
\hline Variable & No. of items & Variables & Cronbach's $\alpha$ & $\begin{array}{l}\text { Standardised } \\
\text { factor loading }\end{array}$ & $\mathbf{C R}$ & AVE \\
\hline \multirow[t]{5}{*}{ Perceived Enjoyment } & 5 & PE9 & .84 & .70 & .84 & .52 \\
\hline & & PE10 & & .71 & & \\
\hline & & PE11 & & .81 & & \\
\hline & & PE12 & & .57 & & \\
\hline & & PE13 & & .75 & & \\
\hline \multirow[t]{6}{*}{ Knowledge Sharing } & 6 & $\mathrm{KS} 20$ & .86 & .60 & .86 & .51 \\
\hline & & $\mathrm{KS} 23$ & & .69 & & \\
\hline & & $\mathrm{KS} 24$ & & .73 & & \\
\hline & & $\mathrm{KS} 25$ & & .78 & & \\
\hline & & KS26 & & .75 & & \\
\hline & & $\mathrm{KS} 27$ & & .72 & & \\
\hline \multirow[t]{5}{*}{ Team Effectiveness } & 5 & TE30 & .87 & .68 & .87 & .54 \\
\hline & & TE31 & & .81 & & \\
\hline & & TE32 & & .78 & & \\
\hline & & TE33 & & .83 & & \\
\hline & & TE34 & & .68 & & \\
\hline Perceived Individual & 5 & PIL1 & .91 & .83 & .91 & .68 \\
\hline \multirow[t]{4}{*}{ Learning } & & PIL2 & & .84 & & \\
\hline & & PIL3 & & .86 & & \\
\hline & & PIL4 & & .88 & & \\
\hline & & PIL6 & & .70 & & \\
\hline
\end{tabular}

Note. $N=197 . \mathrm{AVE}(>.50), \mathrm{CR}(>.70)$

\section{Model-data fit}

CFA was performed for each of the latent variables and the four-factor SEM model was measured using 21 indicators. The results of the proposed model depicted a good fit to the data: $\chi^{2}=282.50, d f=184$, CFI $=$ $.96, \mathrm{TLI}=.95, \mathrm{RMSEA}=.05$, which provided satisfactory model fit indices and evidence of discriminant validity, which decreased the potential influence of common-methods variance (Podsakoff et al., 2003).

\section{Structural model}

The results showed that the direct effect of perceived enjoyment on knowledge sharing was statistically significant (standardised direct effect $=.58, p<.001$ ), the direct effect of perceived enjoyment on team effectiveness was statistically significant (standardised direct effect $=.54, p<.001$ ), and the direct effect of perceived enjoyment on perceived individual learning was also statistically significant (standardised direct effect $=.78, p<.001)$ (see Figure 2 ). Hence, hypotheses 1,2 , and 3 were all supported. The direct effect of knowledge sharing on team effectiveness was statistically significant (standardised direct effect $=$ $.79, p<.001$ ), and the direct effect of knowledge sharing on perceived individual learning was statistically significant (standardised direct effect $=.64, p<.001$ ). Hence, hypotheses 4 and 5 were supported.

\section{Mediating effect}

In order to investigate the indirect effect of perceived enjoyment on the two outcome variables through the "knowledge-sharing" mediator, we conducted bias-corrected bootstrapping and percentile bootstrapping at a 95\% confidence interval using 5000 bootstrap samples (Taylor, MacKinnon, \& Tein, 2008). Further, following the suggestions of Preacher and Hayes (2008), we calculated the confidence intervals of the lower and upper bounds to see whether zero was included in the specific interval in order to determine the significance of the indirect effect. Tables 3 and 4 list the results of the bootstrapping test, which confirmed the existence of a significant intervening effect of knowledge sharing between perceived enjoyment and perceived individual learning, and a significant intervening effect of knowledge sharing between perceived enjoyment and team effectiveness. 
Thus, both hypotheses 4 and 7 were supported. More specifically, the results listed in Table 3 reveal an intervening effect of knowledge sharing between perceived enjoyment and team effectiveness. The $Z$ value of the direct effect in the product of coefficients was 1.341, which is below the 1.96 threshold value. In addition, 0 was included between the bias-correlated upper and lower bounds $(-0.057<0<0.29)$. Thus, there was a full mediating effect. In contrast, since zero was not included between the bias-correlated upper (1.389) and lower bounds (0.799) in Table 4, the direct effect was still significant. Thus, there was a partial mediation effect of knowledge sharing between the perceived enjoyment and the perceived individual learning. Moreover, Figure 2 summarises the results from the hypothesis testing in our evaluation models considering the direct and mediating effects.

Table 3

The mediating effect of knowledge sharing between perceived enjoyment and team effectiveness

\begin{tabular}{|c|c|c|c|c|c|c|}
\hline \multirow{3}{*}{ Point estimation } & \multirow{2}{*}{\multicolumn{2}{|c|}{ Product of coefficients }} & \multicolumn{4}{|c|}{ Bootstrapping } \\
\hline & & & \multicolumn{2}{|c|}{$\begin{array}{c}\text { Bias-corrected } \\
95 \% \text { CI }\end{array}$} & \multicolumn{2}{|c|}{$\begin{array}{c}\text { Percentile } \\
95 \% \text { CI }\end{array}$} \\
\hline & SE & $\bar{Z}$ & Lower & Upper & Lower & Upper \\
\hline \multicolumn{7}{|c|}{ Indirect effect } \\
\hline 0.401 & 0.088 & 4.557 & 0.254 & 0.601 & 0.251 & 0.594 \\
\hline \multicolumn{7}{|c|}{ Direct effect } \\
\hline 0.118 & 0.088 & 1.341 & -0.057 & 0.29 & -0.058 & 0.287 \\
\hline \multicolumn{7}{|c|}{ Total effect } \\
\hline 0.519 & 0.091 & 5.703 & 0.355 & 0.716 & 0.348 & 0.708 \\
\hline
\end{tabular}

Note. Bootstrapping sample of estimation is 5000 .

Table 4

The mediating effect of knowledge sharing between perceived enjoyment and perceived individual learning

\begin{tabular}{|c|c|c|c|c|c|c|}
\hline \multirow{3}{*}{ Point estimation } & \multirow{2}{*}{\multicolumn{2}{|c|}{ Product of coefficients }} & \multicolumn{4}{|c|}{ Bootstrapping } \\
\hline & & & \multicolumn{2}{|c|}{$\begin{array}{c}\text { Bias-corrected } \\
95 \% \text { CI } \\
\end{array}$} & \multicolumn{2}{|c|}{$\begin{array}{c}\text { Percentile } \\
95 \% \text { CI }\end{array}$} \\
\hline & SE & $\mathbf{Z}$ & Lower & Upper & Lower & Upper \\
\hline \multicolumn{7}{|c|}{ Indirect effect } \\
\hline 0.288 & 0.098 & 2.939 & 0.129 & 0.528 & 0.12 & 0.502 \\
\hline \multicolumn{7}{|c|}{ Direct effect } \\
\hline 1.071 & 0.15 & 7.140 & 0.799 & 1.389 & 0.801 & 1.391 \\
\hline \multicolumn{7}{|c|}{ Total effect } \\
\hline 1.359 & 0.139 & 9.777 & 1.117 & 1.661 & 1.12 & 1.669 \\
\hline
\end{tabular}

Note. Bootstrapping sample of estimation is 5000 .

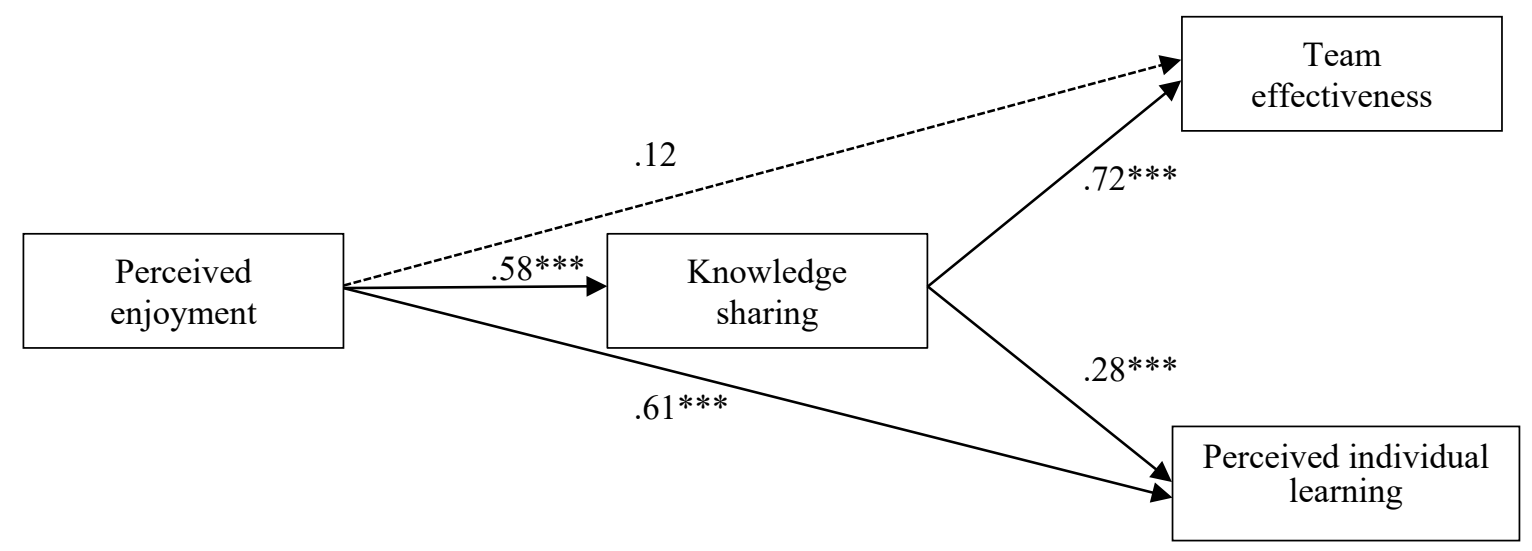

Figure 2. SEM of the hypothesised model

Note. ${ }^{* * *} p<.001, * * p<.01,{ }^{*} p<.05 ; N=197$. 


\section{Discussion}

The purpose of this study was to examine the relationships among the variables of perceived enjoyment, perceived learning, and team effectiveness, and to establish the role of knowledge sharing as a mediator for this relationship. The results of this study suggest that our research framework had a good data-model fit, and the seven proposed hypotheses were all supported. Our evidence suggested that students' perceived enjoyment of this course design played a critical role in the success of the BTBL classroom. The results also indicated that the students who enjoyed this blended business course tended to share knowledge with their team members, which concurred with previous findings (Moghavvemi et al., 2017; S. Wang \& Noe, 2010).

Similar to the findings of previous studies (e.g., Alsharo et al., 2017; Gomez et al., 2010), the students who enjoyed this class most were more likely to perceive that their team worked more efficiently and effectively, and that they had a better learning experience in this type of interaction mode and learning context. The other important finding in this study is that knowledge sharing proved to be a mediator for students' perceived enjoyment, team effectiveness, and perceived individual learning. That result supports the findings of previous studies (Alsharo et al., 2017; Gomez et al., 2010). In addition to enjoying this learning course design, the students who could share their opinions, ideas, and knowledge with their teammates perceived that they had a productive learning experience and that they helped their team perform better.

\section{Conclusions}

BTBL classroom models have become prevalent in higher education because this teaching approach not only encourages instructors to utilise a set of pedagogical approaches and make use of technology, it also provides learners with opportunities for active learning by increasing students' autonomy, engagement, centredness, and connectivity (Abeysekera \& Dawson, 2015; McLaughlin et al., 2014; Roach, 2014; Thai, De Wever, \& Valcke, 2017). Since many factors can influence the design, use, and evaluation of learning spaces that constitute a bridge between business education and targeted workplace domains, we constructed a BTBL classroom model and implemented it in a university business course. We examined several important variables regarding students' perceptions of their enjoyment, knowledge sharing, teamwork, and learning based on the notions of social exchange theory (Bandura, 1977) as well as on social learning theory (Blau, 1964).

The proposed BTBL course design included face-to-face and online modules and was proven to be suitable for course delivery and student learning in business professional development. The results also supported the view that BTBL is an effective teaching method to enhance student learning experiences and their perceived outcomes (Gomez et al., 2010; Haidet, Kubitz, \& McCormack, 2014; J. H. Huang \& Lin, 2017). By placing emphasis on the BTBL course design, BL was adopted to extend traditional brick-and-mortar classrooms to create an interactive and inviting learning environment. The students gained opportunities to interact and communicate with each other both in the face-to-face classroom and the online learning community. Most students enjoyed the incorporation of learning spaces and considered that they had a positive learning experience in this learning context.

The findings also indicated that perceived enjoyment could create dynamic knowledge sharing interactions among team members, during which information exchange was essential to team-based success. Through the processes of knowledge sharing and information exchange, team effectiveness and perceived individual learning seemed to be subsequently improved. Moreover, the findings showed that knowledge sharing appeared to be critical to the success of the BTBL classroom, where the students' interactions and achievements were displayed. These results resonate with the two social theories mentioned above, because the students adapted to learning, working, interacting, and collaborating as a team, and they tended to be more willing to share knowledge when they perceived enjoyment and contributions from their teammates.

This study also noted that the fun and enjoyment generated in the BTBL classroom seemed to impact the students' learning and motivate them to become interested in the learning content and activities. As much as their classroom instruction, the teachers' efforts in the design of the course and tasks could affect the students' engagement with the lessons, and stimulated the occurrence of knowledge sharing during the course time. Once the students formed the habit of knowledge sharing, they were more likely to assist and 
cooperate with their team members through idea communication and information exchange. Knowledge sharing among team members also seemed to enable them to operate better, generate productive outcomes, and achieve better performances due to the contribution of collective intelligence. The participants perceived their learning in the BTBL classroom more favourably when they worked well in teams, which may help them develop targeted competencies and skills by participating in different projects, and therefore boost future personal competitiveness. In brief, the above findings are valuable and insightful for instructors to consider while conducting BTBL.

The research results proved that focusing on the affective domains of BTBL, in particular the learners' perceived enjoyment, appeared to be essential and beneficial to individual learning and team effectiveness. Thus, the instructors in BTBL classrooms would be wise to construct an enjoyable and engaging learning environment that motivates students to learn and encourages them to participate. When individuals feel motivated and enjoy the courses, they may be more willing to share knowledge and provide support in a group setting, which will prompt them to communicate openly and exchange ideas. Working in teams may allow them to reciprocate as they contribute mutual expertise and insights during collective problemsolving and participatory decision-making processes. When members of a team are willing to share useful information and knowledge towards targeted tasks, the team could achieve goals in more effective and meaningful ways due to cohesiveness and reciprocity. With BTBL, dynamic processes could deepen learners' understanding of the course content via knowledge sharing during in-depth conversations and team collaboration.

\section{Limitations and future directions}

In this study, we examined BTBL in support of undergraduate business courses and the findings offered insights to guide future research into student enjoyment, knowledge sharing, individual learning, and team effectiveness in blended classrooms. However, this research had four limitations. First and foremost, the current study was conducted in a specific context, namely a human resource management course in two Taiwanese universities. Thus, the results might not be easily generalised to other educational and cultural contexts. Further research could apply this research framework and confirm the findings of this study. Second, this study only collected students' perceptions, rather than their actual learning outcomes (e.g., tests or project scores). Consequently, the causal relationship between the design of BTBL and students' learning effectiveness and performance cannot be decided and should not be overinterpreted. Third, this research study adopted a quantitative approach to collect data. Qualitative data (e.g., classroom observations, learners' discussion logs, or assignments) could be used for future research analysis as well. Fourth, the research design was conducted in cross-sectional and self-reported fashions. The problem of CMV was not sufficiently serious based on the Harman's single factor test. To minimise or prevent such biases, it is recommended that further studies select appropriate procedural and statistical remedies in terms of survey questionnaire design and data collection (Podsakoff et al., 2003). Last, deepening our understanding about the capabilities of BTBL is necessary to foster its pedagogical application and effectiveness. The current research framework could be used to supplement previous research directions, and future research could investigate the roles of interaction and cooperation between students in BTBL classrooms to enhance their learning outcomes and innovative thinking. Another interesting development would be an investigation as to how different students with varied personality traits and learning styles develop their strategies in BTBL classrooms.

\section{Acknowledgements}

This work was supported by Ministry of Science and Technology of Taiwan for its research grant support (MOST 107-2410-H-141-011 and MOST 107-2410-H-305-058).

\section{References}

Abeysekera, L., \& Dawson, P. (2015). Motivation and cognitive load in the flipped classroom: Definition, rationale and a call for research. Higher Education Research \& Development, 34(1), 1-14.

https://doi.org/10.1080/07294360.2014.934336 
Alammary, A., Sheard, J., \& Carbone, A. (2014). Blended learning in higher education: Three different design approaches. Australasian Journal of Educational Technology, 30(4), 440-454. https://doi.org/10.14742/ajet.693

Alsharo, M., Gregg, D., \& Ramirez, R. (2017). Virtual team effectiveness: The role of knowledge sharing and trust. Information \& Management, 54(4), 479-490. https://doi.org/10.1016/j.im.2016.10.005

Arbaugh, J. B. (2014). System, scholar or students? Which most influences online MBA course effectiveness? Journal of Computer Assisted Learning, 30(4), 349-362. https://doi.org/10.1111/jcal.12048

Arbaugh, J. B., Godfrey, M. R., Johnson, M., Pollack, B. L., Niendorf, B., \& Wresch, W. (2009). Research in online and blended learning in the business disciplines: Key findings and possible future directions. The Internet and Higher Education, 12(2), 71-87. https://doi.org/10.1016/j.iheduc.2009.06.006

Arney, L. (2015). Go blended!: A handbook for blending technology in schools. San Francisco, CA: John Wiley \& Sons.

Audebrand, L. K., Camus, A., \& Michaud, V. (2017). A mosquito in the classroom: Using the cooperative business model to foster paradoxical thinking in management education. Journal of Management Education, 41(2), 216-248. https://doi.org/10.1177/1052562916682552

Bagozzi, R.P. \& Yi, Y. (1989). On the evaluation of structural equation models. Journal of Academy Marketing Science, 16, 74-94. https://doi.org/10.1007/BF02723327

Bandura, A. (1977). Social learning theory. Englewood Cliffs, NJ: Prentice-Hall.

Blau, P. M. (1964). Exchange and power in social life. New York, NY: John Wiley.

Bock, G. W., Zmud, R. W., Kim, Y. G., \& Lee, J. N. (2005). Behavioral intention formation in knowledge sharing: Examining the roles of extrinsic motivators, social-psychological forces, and organizational climate. MIS Quarterly, 87-111. https://doi.org/10.2307/25148669

Brown, M. G. (2016). Blended instructional practice: A review of the empirical literature on instructors' adoption and use of online tools in face-to-face teaching. The Internet and Higher Education, 31, 110. https://doi.org/10.1016/j.iheduc.2016.05.001

Caza, A., Brower, H. H., \& Wayne, J. H. (2015). Effects of a holistic, experiential curriculum on business students' satisfaction and career confidence. The International Journal of Management Education, 13(1), 75-83. https://doi.org/10.1016/j.ijme.2015.01.006

Daspit, J. J., \& D’Souza, D. E. (2012). Using the community of inquiry framework to introduce wiki environments in blended-learning pedagogies: Evidence from a business capstone course. Academy of Management Learning \& Education, 11(4), 666-683. https://doi.org/10.5465/amle.2010.0154

Dutta, S. (1997). Strategies for implementing knowledge-based systems. IEEE Transactions on Engineering Management, 44(1), 79-90. https://doi.org/10.1109/17.552810

Fornell, C., \& Larcker, D. F. (1981). Evaluating structural equation models with unobservable variables and measurement error. Journal of Marketing Research, 18(1), 39-50. https://doi.org/10.1177/00222 4378101800104

Garrison, D. R., \& Kanuka, H. (2004). Blended learning: Uncovering its transformative potential in higher education. The Internet and Higher Education, 7(2), 95-105. https://doi.org/10.1016/j.iheduc.2004.02.001

Garrison, D. R., \& Vaughan, N. D. (2008). Blended learning in higher education: Framework, principles, and guidelines. Hoboken, NJ: John Wiley \& Sons.

Garrison, D. R., \& Vaughan, N. D. (2013). Institutional change and leadership associated with blended learning innovation: Two case studies. The Internet and Higher Education, 18, 24-28. https://doi.org/10.1016/j.iheduc.2012.09.001

Gomez, E. A., Wu, D., \& Passerini, K. (2010). Computer-supported team-based learning: The impact of motivation, enjoyment and team contributions on learning outcomes. Computers \& Education, 55(1), 378-390. https://doi.org/10.1016/j.compedu.201 0.02.003

Haidet, P., Kubitz, K., \& McCormack, W. T. (2014). Analysis of the team-based learning literature: TBL comes of age. Journal on Excellence in College Teaching, 25(3-4), 303-333. Retrieved from https://www.ncbi.nlm.nih.gov/pmc/articles/PMC4643940

Hair, J., Black, W., Babin, B., \& Anderson, R. (2010). Multivariate data analysis (7th ed.). Upper Saddle River, NJ: Prentice-Hall.

Hooper, D., Coughlan, J., \& Mullen, M. (2008). Structural equation modelling: Guidelines for determining model fit. Electronic Journal of Business Research Methods, 6(1), 53-60. https://doi.org/10.21427/D7CF7R 
Huang, C. K., \& Lin, C. Y. (2017). Flipping business education: Transformative use of team-based learning in human resource management classrooms. Educational Technology \& Society, 20(1), 323336. Retrieved from https://www.j-ets.net/ETS/journals/20 1/27.pdf

Huang, J. H., Lin, Y. R., \& Chuang, S. T. (2007). Elucidating user behavior of mobile learning: A perspective of the extended technology acceptance model. The Electronic Library, 25(5), 585-598. https://doi.org/10.1108/02640470710829569

Hung, M. L., \& Chou, C. (2015). Students' perceptions of instructors' roles in blended and online learning environments: A comparative study. Computers \& Education, 81, 315-325. https://doi.org/10.1016/j.compedu.20 14.10.022

Hung, S.-W., \& Cheng, M.-J. (2013). Are you ready for knowledge sharing? An empirical study of virtual communities. Computers \& Education, 62, 8-17. https://doi.org/10.1016/j.comped u.2012.09.017

Hsu, C. L., \& Lin, J. C. C. (2008). Acceptance of blog usage: The roles of technology acceptance, social influence and knowledge sharing motivation. Information \& Management, 45(1), 65-74. https://doi.org/10.1016/j.im.2007.11.001

Jonassen, D., \& Land, S. (2012). Theoretical foundations of learning environments (2nd ed.). New York, NY: Routledge.

Kankanhalli, A., Tan, B. C., \& Wei, K. K. (2005). Contributing knowledge to electronic knowledge repositories: An empirical investigation. MIS Quarterly, 29(1), 113-143. https://doi.org/10.2307/25148670

Lai, K.-W. (2011). Digital technology and the culture of teaching and learning in higher education. Australasian Journal of Educational Technology, 27(8), 1263-1275. https://doi.org/10.14742/ajet.892

Lu, L., Lin, X., \& Leung, K. (2012). Goal orientation and innovative performance: The mediating roles of knowledge sharing and perceived autonomy. Journal of Applied Social Psychology, 42(S1). E180E197. https://doi.org/10.1111/j.1559-1816.2012.01018.x

Lurey, J. S., \& Raisinghani, M. S. (2001). An empirical study of best practices in virtual teams. Information \& Management, 38(8), 523-544. https://doi.org/10.1016/S0378-7206(01)0007 4-X

Ma, W. W. K., \& Yuen, A. H. K. (2011). Understanding online knowledge sharing: An interpersonal relationship perspective. Computers \& Education, 56(1), 210-219. https://doi.org/10.1016/j.compedu.2010.08.004

McLaughlin, J., Roth, M., Glatt, D., Gharkholonarehe, N., Davidson, C., LaToya, G., et al. (2014). The flipped classroom: A course redesign to foster learning and engagement in a health professions school. Academic Medicine, 89(2), 236-243. https://doi.org/10.1097/ACM.0000000000000086

McLoughlin, C., \& Luca, J. (2002). A learner-centered approach to developing team skills through webbased learning and assessment. British Journal of Educational Technology, 33(5), 571-582. https://doi.org/10.1111/1467-8535.00292

Mirriahi, N., Alonzo, D., McIntyre, S., Kligyte, G., \& Fox, B. (2015). Blended learning innovations: Leadership and change in one Australian institution. International Journal of Education and Development using Information and Communication Technology, 11(1), 4-16. Retrieved from http://ijedict.dec.uwi.edu/viewissue.php?id=41

Moghavvemi, S., Sharabati, M., Paramanathan, T., \& Rahin, N. M. (2017). The impact of perceived enjoyment, perceived reciprocal benefits and knowledge power on students' knowledge sharing through Facebook. The International Journal of Management Education, 15(1), 1-12. https://doi.org/10.1016/j.ijme.2016.11.002

Nelson, K. M., \& Cooprider, J. G. (1996). The contribution of shared knowledge to IS group performance. MIS Quarterly, 409-432. https://doi.org/10.2307/249562

Oh, S., \& Syn, S. Y. (2015). Motivations for sharing information and social support in social media: A comparative analysis of Facebook, Twitter, Delicious, YouTube, and Flickr. Journal of the Association for Information Science and Technology, 66(10), 2045-2060. https://doi.org/10.1002/asi.23320

Owston, R., York, D., \& Malhotra, T. (2019). Blended learning in large enrolment courses: Student perceptions across four different instructional models. Australasian Journal of Educational Technology, 35(5), 29-45. https://doi.org/10.14742/ajet.4310

Owston, R., York, D., \& Murtha, S. (2013). Student perceptions and achievement in a university blended learning strategic initiative. The Internet and Higher Education, 18, 38-46. https://doi.org/10.1016/j.iheduc.2012.12.003

Pangil, F., \& Chan, J. M. (2014). The mediating effect of knowledge sharing on the relationship between trust and virtual team effectiveness. Journal of Knowledge Management, 18(1), 92-106.

https://doi.org/10.1108/JKM-09-2013-0341 
Pinto-Llorente, A. M., Sánchez-Gómez, M. C., García-Peñalvo, F. J., \& Casillas-Martín, S. (2017). Students' perceptions and attitudes towards asynchronous technological tools in blended-learning training to improve grammatical competence in English as a second language. Computers in Human Behavior, 72, 632-643. https://doi.org/10.1016/j.chb.2016.05.071

Podsakoff, P. M., MacKenzie, S. B., Lee, J.-Y., \& Podsakoff, N. P. (2003). Common method biases in behavioral research: A critical review of the literature and recommended remedies. Journal of Applied Psychology, 88(5), 879-903. https://doi.org/10.1037/0021-9010.8 8.5.879

Porter, W. W., Graham, C. R., Spring, K. A., \& Welch, K. R. (2014). Blended learning in higher education: Institutional adoption and implementation. Computers \& Education, 75, 185-195. https://doi.org/10.1016/j.comp edu.2014.02.011

Preacher, K. J., \& Hayes, A. F. (2008). Contemporary approaches to assessing mediation in communication research. In A. F. Hayes, M. D. Slater, \& L. B. Snyder (Eds.), The Sage sourcebook of advanced data analysis methods for communication research (pp. 13-54). Thousand Oaks, CA: Sage.

Ritke-Jones, W. (Ed.). (2010). Virtual environments for corporate education: Employee learning and solutions. Hershey, PA: IGI Global.

Ritter, B. A., Small, E. E., Mortimer, J. W., \& Doll, J. L. (2018). Designing management curriculum for workplace readiness: Developing students' soft skills. Journal of Management Education, 42(1), 80103. https://doi.org/10.1177/1052562917703679

Roach, T. (2014). Student perceptions toward flipped learning: New methods to increase interaction and active learning in economics. International Review of Economics Education, 17, 74-84. https://doi.org/10.1016/j.iree.2014.08.003

Rovai, A. P. (2002). Sense of community, perceived cognitive learning, and persistence in asynchronous learning networks. The Internet and Higher Education, 5(4), 319-332. https://doi.org/10.1016/S1 0967516(02)00130-6

Senge, P. (1997). Sharing knowledge: The leader's role is key to a learning culture. Executive Excellence, 14, 17-17.

Severt, K., Fjelstul, J., \& Breiter, D. (2013). Information communication technologies: Usages and preferences of generation Y students and meeting professionals. Journal of Convention \& Event Tourism, 14(2), 124-143. https://doi.org/10.1080/15470148.2013.781487

Singh, H. (2003). Building effective blended learning programs. Educational Technology, 43(6), 51-54.

Slagter van Tryon, P. J., \& Bishop, M. J. (2009). Theoretical foundations for enhancing social connectedness in online learning environments. Distance Education, 30(3), 291-315. https://doi.org/10.1080/01587910903236312

Smyth, S., Houghton, C., Cooney, A., \& Casey, D. (2012). Students' experiences of blended learning across a range of postgraduate programs. Nurse Education Today, 32(4), 464-468. https://doi.org/10.1016/j.nedt.2011.05.014

Szeto, E. (2015). Community of Inquiry as an instructional approach: What effects of teaching, social and cognitive presences are there in blended synchronous learning and teaching? Computers \& Education, 81, 191-201. https://doi.org/10.1016/j.compedu.2014.10.015

Taylor, A. B., Mackinnon, D., \& Tein, J.-Y. (2008). Tests of the three-path mediated effect. Organizational Research Methods, 11(2), 241269. https://doi.org/10.1177/1094428107300344

Thai, N. T. T., De Wever, B., \& Valcke, M. (2017). The impact of a flipped classroom design on learning performance in higher education: Looking for the best "blend" of lectures and guiding questions with feedback. Computers \& Education, 107, 113-126. https://doi.org/10.1016/j.compedu.2017.01.003

Timmerman, J. E., \& Morris, R. F. (2015). Creation of exercises for team-based learning in business. International Journal of Teaching and Learning in Higher Education, 27(2), 280-291. Retrieved from http://www.isetl.org/ijtlhe/pdf/IJTLHE1973.pdf

Urh, M., Vukovic, G., Jereb, E., \& Pintar, R. (2015). The model for introduction of gamification into elearning in higher education. Procedia-Social and Behavioral Sciences, 197, 388-397. https://doi.org/10.1016/j.sbspro.2015.07.154

Vaughan, N. (2007). Perspectives on blended learning in higher education. International Journal on ELearning, 6(1), 81-94. Retrieved from https://learntechlib.org/primary/p/6310/

Vygotsky, L. (1978). Mind in society: The development of higher mental process. Cambridge, MA: Harvard University Press.

Wang, M. H., Yang, T. Y., \& Wu, C. S. (2006). The impact of ISD team members' self-efficacy, team interaction and team trust on team effectiveness: The mediating effect of knowledge sharing. NTU 
Management Review, 16(2), 73-99. Retrieved from http://review.management.ntu.edu.tw/vol file.aspx?lang=en\&fid=O-393

Wang, S., \& Noe, R. A. (2010). Knowledge sharing: A review and directions for future research. Human Resource Management Review, 20(2), 115-131. https://doi.org/10.1016/j.hrmr.2009.10.001

Wanner, T., \& Palmer, E. (2015). Personalizing learning: Exploring student and teacher perceptions about flexible learning and assessment in a flipped university course. Computers \& Education, 88, 354-369. https://doi.org/10.1016/j.compedu.2015.07.008

Wertsch, J. V., \& Bivens, J. A. (1992). The social origins of individual mental functioning: Alternatives and perspectives. Quarterly Newsletter of the Laboratory of Comparative Human Cognition, 14(2), 35-43. Retrieved from http://lchc.ucsd.edu/Histarch/ap92v14n2.PDF

Whitaker, J., New, J. R., \& Ireland, R. D. (2016). MOOCs and the online delivery of business education What's new? What's not? What now? Academy of Management Learning \& Education, 15(2), 345365. https://doi.org/10.5465/amle.2013.0021

Corresponding author: Chung-Kai Huang, hck2005@ntub.edu.tw

Copyright: Articles published in the Australasian Journal of Educational Technology (AJET) are available under Creative Commons Attribution Non-Commercial No Derivatives Licence (CC BY-NC-ND 4.0). Authors retain copyright in their work and grant AJET right of first publication under CC BY-NC-ND 4.0 .

Please cite as: Lin, C.-Y., Huang, C.-K., \& Ko, C.-J. (2020). The impact of perceived enjoyment on team effectiveness and individual learning in a blended learning business course: The mediating effect of knowledge sharing. Australasian Journal of Educational Technology, 36(1), 126-141.

https://doi.org/10.14742/ajet.4446 


\section{Appendix}

Perceived Enjoyment (PE)

PE1: I enjoyed sharing my knowledge of course related materials with my team through BTBL.

PE2: I enjoyed BTBL more than regular classes with lectures.

PE3: I like BTBL.

PE4: BTBL improved my communication skills.

PE5: I found myself more interested in the subject with BTBL

Knowledge Sharing (KS)

KS1: When I ask team members questions, they try their best to answer me.

KS2: Team members often share their knowledge and experience with others voluntarily and proactively.

KS3: Team members try to understand others' viewpoints.

KS4: When team members discuss questions, all members try to provide their own opinions.

KS5: Team members can accept new viewpoints and ways of thinking.

KS6: Team members look at an issue from various angles

KS7: Overall, team members share knowledge about work successfully.

KS8: Team members can clearly elaborate their viewpoints.

Team Effectiveness (TE)

TE1: Team members can finish their tasks in time.

TE2: All team members are expected.

TE3: Each team member's contribution is valuable.

TE4: Team participation makes team members enhance their learning satisfaction.

TE5: Team participation makes team members have more trust.

TE6: Team participation makes team members have more growth satisfaction.

TE7: Overall, teams can achieve expected outcomes.

Perceived Individual Learning (PIL)

PIL1: The learning quality of course materials was improved by the team activities.

PIL2: BTBL has broadened my knowledge of course related materials.

PIL3: BTBL improved my ability to integrate concepts from different parts of the semester's materials.

PIL4: BTBL was useful to my learning.

PIL5: I learned a great deal from my team. 